\title{
Propolis: An Enrichment Material for Mycelium Development of Oyster Mushroom (Pleurotus ostreatus)
}

\author{
İbrahim Türkekul*, Yaşar Gülmez \\ Department of Biology, Faculty of Science and Arts, Gaziosmanpaşa University, Tokat, Turkey \\ Email: "turkoibrahim@yahoo.com
}

Received 27 January 2016; accepted 8 March 2016; published 11 March 2016

Copyright (C) 2016 by authors and Scientific Research Publishing Inc.

This work is licensed under the Creative Commons Attribution International License (CC BY). http://creativecommons.org/licenses/by/4.0/

cC) (7) Open Access

\begin{abstract}
The effect of propolis, taken from honeybee hives in Tokat (Turkey), on mycelium development of oyster mushroom (Pleurotus ostreatus) was investigated. Propolis contains various chemical compounds and has antiviral, antibacterial and antifungal activities. Mushroom spores were inoculated in Potato Dextrose Agar (PDA) media containing different proportions of propolis. Mycelium development on media containing $0.10 \%, 0.30 \%$, and $0.50 \%$ propolis occured at the first, third, and fifth days, respectively. The fastest and most intense development was seen on medium containing $\mathbf{0 . 1 0 \%}$ propolis. According to our results, propolis can be used as an enriching material in mushroom cultivating.
\end{abstract}

Keywords

Propolis, Pleurotus ostreatus, Mycelium Development, Turkey

\section{Introduction}

Mushrooms are very rich in amino acids, vitamins, and minerals; therefore they are very important in human nutrition and health [1]. Population growth and increasing food requirement in the world enhances the importance of natural products such as mushrooms. Thus, mushroom cultivation can be one of the most significant sectors in meeting food needs. Many species of mushrooms are grown in the world and demand for them is increasing steadily.

Pleurotus genus is found in Pleurotaceae family, Agaricales order, Agaricomycetes class and Basidiomycoata phylum. Oyster mushroom (Pleurotus ostreatus (Fr. Kummer)), also known as "poplar mushroom" or "tree

${ }^{*}$ Corresponding author. 
mushroom", grows naturally on hardwood or decaying conifer, poplar and beech trees in tropical and temperate climates throughout the world [2] [3], but it is also commonly cultivated and among the most popular mushrooms. It is preferred due to its excellent flavor, high nutritional value, long shelf life and high biological efficiency [4]-[6].

Mycelia, found under the soil, are the main structures forming the mushroom and very important in mushroom cultivation [7]. During development, mycelia take mineral substances and water from the environment and form edible parts of the mushroom. Mycelium development is one of the most important factors that have a direct effect on productivity of mushroom cultivation. For this reason, enrichment of mycelial growth media as well as preventing it from contamination may help to improve productivity. Favorable effect of propolis on mycelium development of some mushrooms has been demonstrated by previous studies. For example Güler et al. [8] showed positive effect of propolis on mycelium development of Morchella conica and Güler et al. [9] reported that propolis directly increased mycelium development and product amount in Agaricus bitorquis.

Propolis is a kind of resin collected from plant shoots by honeybees which is then stored in the hive. It has antibacterial, antifungal, and antiviral effects [10] [11]. It contains many chemical compounds and is very rich in amino acids, aliphatic acids, aromatic acids, aromatic acid esters, aromatic aldehydes, flavons, ketons, and terpenoids [12] [13]. Propolis, due to its biological activities, may have an efficient role in preventing medium from contamination during mycelial growth. In this study, the effect of propolis on mycelium development of oyster mushroom Pleurotus ostreatus, was investigated.

\section{Materials and Methods}

\subsection{Material}

Mushrooms (Pleurotus ostreatus), produced in Agricultural Research and Application Center, Gaziosmanpaşa University, Tokat (Turkey) in 2014 were used in the study. Mushrooms were placed on a sterile paper, with gills opposite to direction of gravity, and completely covered with petri dishes. Spore prints were obtained after 12 to 24 hours. $0.10 \%, 0.30 \%$, and $0.50 \%$ propolis extractions were added to Potato Dextrose Agar medium and mycelium development was followed.

\subsection{Main Culture}

Spores obtained from Pleurotus ostreatus fructifications were inoculated on PDA medium by multi-spore inoculation method. Primary mycelia grew after inoculation and homokaryon cultures were obtained. Agar discs were selected from the best grown 10 mycelia and transferred to petri dishes and then incubated for ten days at $27^{\circ} \mathrm{C}$. Secondary mycelium development was observed and heterokaryon cultures were obtained [14]. Mycelium development was measured until they covered 3/4 of petri dishes. Developed mycelia were stored at $+4^{\circ} \mathrm{C}$.

\subsection{Extraction Procedure}

Propolis samples were taken from honeybee hives in Tokat. Propolis samples were ground and kept for 24 hours to obtain powder. Powdery propolis was weighed and ethyl alcohol was added with a ratio of 1:3 (g/ml), which is then stirred for five hours at $500 \mathrm{rpm}$ by heating stirrer at $+35^{\circ} \mathrm{C}$. The solution was stored at $+4^{\circ} \mathrm{C}$ for a month and during this period regularly stirred every day. At the end of this period, the solution was stirred for five hours by heating stirrer at $+35^{\circ} \mathrm{C}$ once again. The solution was filtered by using Whatman 1 and Whatman 2 papers together in a funnel. This extraction was prepared twice. $1.5 \mathrm{ml}$ of extract was taken by glass pipette and evaporated to dryness. The residue was heated to $80^{\circ} \mathrm{C}-100^{\circ} \mathrm{C}$ for 20 minutes in $75 \mu$ dry pyridine and $50 \mu 1$ bis (trimethylsilyl) trifluoroacetamide (BSTFA) solutions (stock 1). 0.5 cc stock 1 was diluted by 10 cc pure ethyl alcohol (99\%) and stock 2 was obtained. $0.10,0.30$ and 0.50 cc propolis extract was taken from stock 2 and mixed with $1000 \mathrm{cc}$ distilled water, then $33.6 \mathrm{~g}$ PDA was added to each of the extracts. The mixture was sterilized at $121^{\circ} \mathrm{C}$ for 15 minutes and poured into sterile petri dishes, which formed the solid propolis added medium after cooling [15]-[18].

\subsection{Mycelium Transfer}

Mycelial agar discs $(0.9 \mathrm{~mm}$ diameter) were centrally inoculated to media with propolis $(0.10 \%, 0.30 \%$ and $0.50 \%$ proportions) and without propolis (control group). Mycelium development was observed and recorded for 
20 days during incubation at $28^{\circ} \mathrm{C}$ (Figure 1).

\subsection{Spawn Preparation}

Spawn was obtained by placing mushroom culture onto steam-sterilized wheat grain (Triticum aestivum L.). For this purpose, $5 \mathrm{~kg}$ grain was boiled for 20 minutes, then filtered and partially dried (to a moisture of $75 \%$ $80 \%$ ). $25 \mathrm{~g}$ lime, to regulate $\mathrm{pH}$ of the medium, and $100 \mathrm{~g}$ plaster, to prevent wheat grains from sticking together, were added to the mixture. The mixture was transferred into 1 lt glass bottles up to $2 / 3$ of its volume and sterilized at $121^{\circ} \mathrm{C}$ for 45 minutes. When wheat grain cooled, mycelial agar discs that were developed previously in PDA medium were added and allowed for incubation at $28^{\circ} \mathrm{C}$. During incubation, bottles were shaken twice a day in order to prevent wheat grains sticking together. Mycelia obtained were stored at $+4^{\circ} \mathrm{C}$ (Figure 2).

\section{Results and Discussions}

Pleurotus ostreatus is a popular mushroom species cultivated on various substrates and enriched media, such as agricultural by-products, weeds, and wastes [19] [20]. Having direct effect on productivity, mycelium development is a vital process in mushroom cultivation. Mushrooms get their food from the environment by means of mycelia. Mycelial growth rate, obtaining good quality spawns and product contamination is among important factors affecting productivity [21]. Propolis, as an enrichment material to growth media, may help to overcome such problems and improve productivity by promoting mycelial development as well as preventing it from contamination.

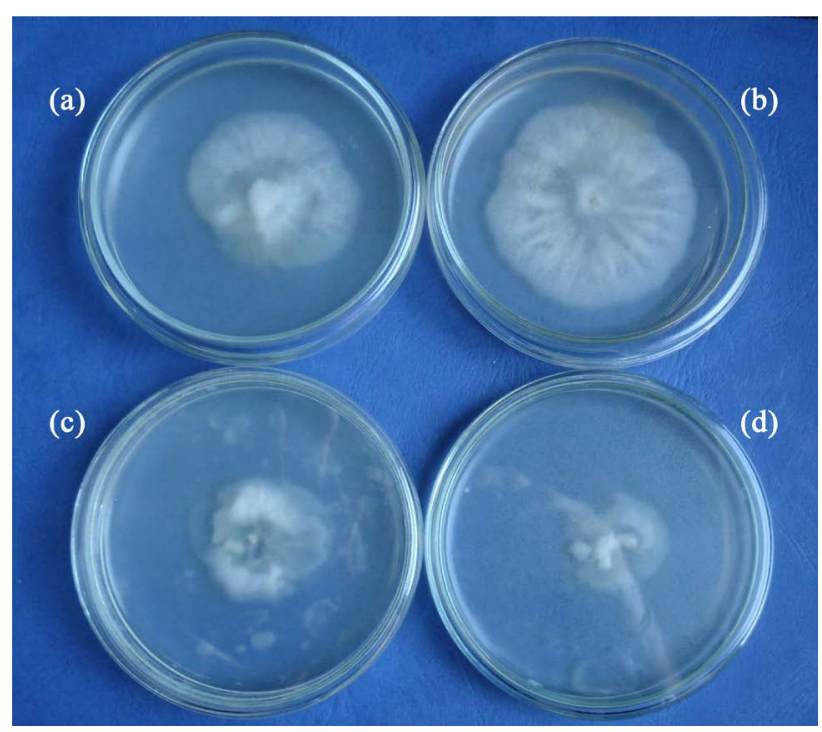

Figure 1. Mycelium development of groups (1 week). (a) Control; (b) 0.1 group; (c) 0.3 group; (d) 0.5 group.

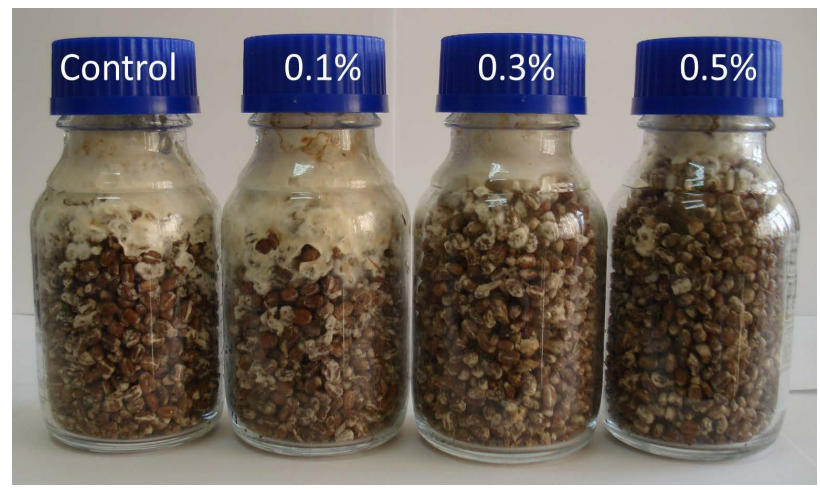

Figure 2. Spawn at different propolis concentrations. 


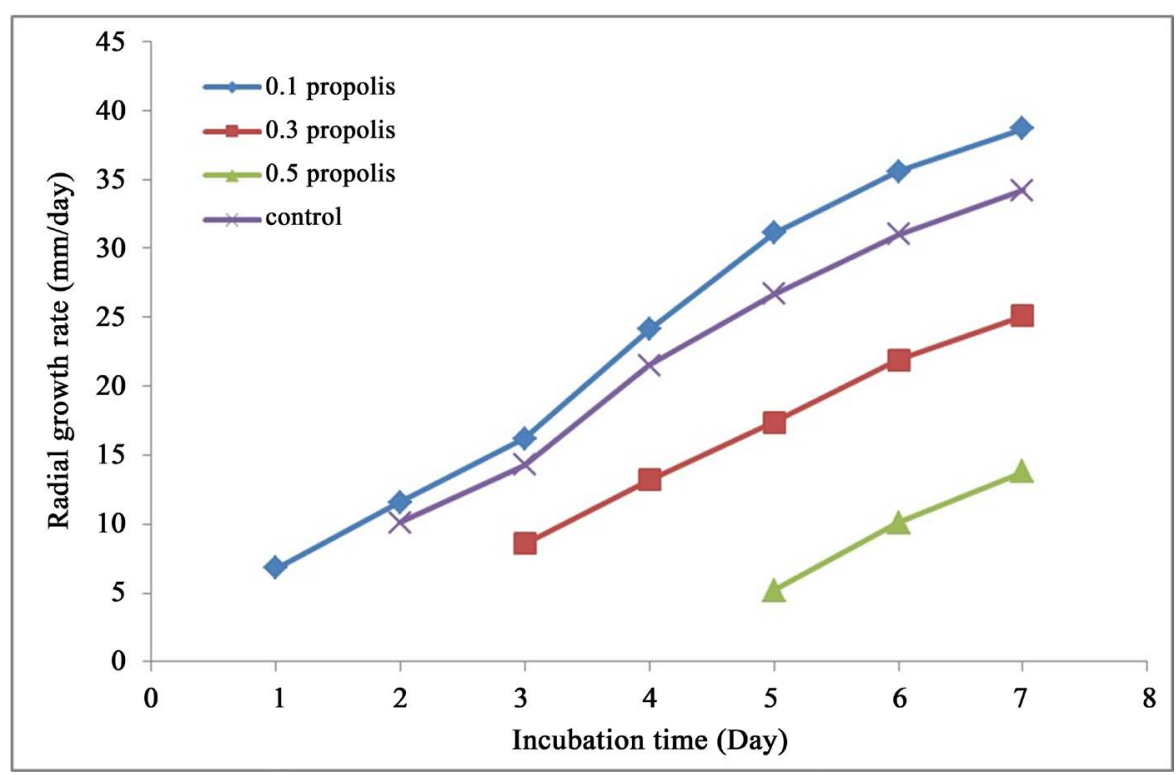

Figure 3. Mycelial development curves of groups.

In this study, we investigated mycelium development in PDA medium enriched with propolis. Mycelium development on PDA media containing $0.10 \%, 0.30 \%$ and $0.50 \%$ propolis occurred at the first, third and fifth days, respectively. Growth began at the second day in the propolis-free control medium. The fastest and most intense development was seen on medium containing $0.10 \%$ propolis (Figure 3). The results show that mycelia grew in a short time and increased the spawn quality in propolis added medium.

Our study showed that propolis may be thought as an additional nutrient in oyster mushroom mycelial growth media. Further research is needed to determine and compare nutritional value of mushrooms cultivated in propolis-enriched media with that of other media.

\section{References}

[1] Deepalakshmi, K. and Mirunalini, S. (2014) Pleurotus ostreatus: An Oyster Mushroom with Nutritional and Medicinal Properties. Journal of Biochemical Technology, 5, 718-726.

[2] Miles, P.G. and Chang, S.-T. (2004) Pleurotus: A Mushroom of Broad Adaptability. Mushrooms: Cultivation, Nutritional Value, Medicinal Effect, and Environmental Impact. 2nd Edition, CRC Press, Boca Raton, 315-325.

[3] Cohen, R., Persky, L. and Hadar, Y. (2002) Biotechnological Applications and Potential of Wood-Degrading Mushrooms of the Genus Pleurotus. Applied Microbiology and Biotechnology, 58, 582-594. http://dx.doi.org/10.1007/s00253-002-0930-y

[4] Mane, V.P., Patil, S.S., Syed, A.A. and Baig, M.M.V. (2007) Bioconversion of Low Quality Lignocellulosic Agricultural Waste into Edible Protein by Pleurotus sajor-caju (Fr.) Singer. Journal of Zhejiang University SCIENCE B, 8, 745-751. http://dx.doi.org/10.1631/jzus.2007.B0745

[5] Ogundele, G.F., Abdulazeez, R.O. and Bamidele, O.P. (2014) Effect of Pure and Mixed Substrate on Oyster Mushroom (Pleurotus ostreatus) Cultivation. Journal of Experimental Biology and Agricultural Sciences, 2, 215-219.

[6] Bhattacharjya, D.K., Paul Md., R.K., Miah, N. and Uddin, A.K. (2015) Comparative Study on Nutritional Composition of Oyster Mushroom (Pleurotus ostreatus Fr.) Cultivated on Different Sawdust Substrates. Bioresearch Communications, 1, 93-98.

[7] Kaşık, G. (2010) Mantar Bilimi. Marifet Matbaave Kağıtçılık, Konya.

[8] Güler, P., Bozcuk, S., Mutlu, F. and Sorkun, K. (2000) The Effect of Propolis on Sclerotial Formations of Morchellaconica Pers. 12th Congress of the Federation of European Societies of Plant Physiology, Budapest, 21-25 August 2000, Budapest-Hungary.

[9] Güler, P., Sorkun, K. and Salih, B. (2003) Effect of Some Propolis on the Product Quantity of Agaricus bisporus (Lange) Sing. Pakistan Journal of Botany, 35, 439-447.

[10] Yu, Q.L., Jun, W., Hong, L., Yun, Q.H. and Bo, L.W. (1999) Study on the Antimicrobial Properties of Propolis. Api- 
culture of China, 50, 5-6.

[11] Katircioğlu, H. and Mercan, N. (2006) Antimicrobial Activity and Chemical Compositions of Turkish Propolis from Different Regions. African Journal of Biotechnology, 5, 1151-1153.

[12] Bankova, V.S., Castro, S.L.D and Marcucci, M.C. (2000) Propolis: Recent Advances in Chemistry and Plant Origin. Apidologie, 31, 3-15. http://dx.doi.org/10.1051/apido:2000102

[13] Velikova, M., Bankova, V., Sorkun, K., Houcine, S., Tsvetkova, I. and Kujumgiev, A. (2000) Propolis from the Mediterranean Region: Chemical Composition and Antimicrobial Activity. Zeitschrift für Naturforschung C, 55, 790-793.

[14] Raper, A.C. (1978) Sexuality and Breeding. In: Chang, S.T. and Hayes, W.A., Eds., The Biology and Cultivation of Edible Mushrooms, Academic Press, New York, San Francisco, London, 83-117.

[15] Güler, P., Çelemli, Ö.G. and Sorkun, K. (2011) Agaricus bitorquis (Quel) Saccardo' in Misel Gelişimive Yetiştirilmesine Propolisin Etkileri. Ecological Life Sciences, 6, 1-13.

[16] Uzel, A., Sorkun, K., Önçağ, Ö., Çoğulu, D., Gençay, Ö. and Salih, B. (2005) Chemical Compositions and Antimicrobial Activities of Four Different Anatolian Propolis Samples. Microbiological Research, 160, 189-195. http://dx.doi.org/10.1016/i.micres.2005.01.002

[17] Popovaa, M., Silici, S., Kaftanoğlu, O. and Bankovaa, V. (2005) Antibacterial Activity of Turkish Propolis and Its Qualitative and Quantitative Chemical Composition. Phytomedicine, 12, 221-228. http://dx.doi.org/10.1016/j.phymed.2003.09.007

[18] Kalogeropoulos, N., Konteles, S.J., Troullidou, E., Mourtzinos, I. and Karathanos, V.T. (2009) Chemical Composition, Antioxidant Activity and Antimicrobial Properties of Propolis Extracts from Greece and Cyprus. Food Chemistry, 116, 452-461. http://dx.doi.org/10.1016/j.foodchem.2009.02.060

[19] Gregori, A., Svagelj, M. and Pohleven, J. (2007) Cultivation Techniques and Medicinal Properties of Pleurotus spp. Food Technology and Biotechnology, 45, 238-249.

[20] Sánchez, C. (2010) Cultivation of Pleurotus ostreatus and Other Edible Mushrooms. Applied Microbiology and Biotechnology, 85, 1321-1337. http://dx.doi.org/10.1007/s00253-009-2343-7

[21] Guadarrama-Mendoza, P.C., Valencia del Toro, G., Ramírez-Carrillo, R., Robles-Martínez, F., Yáñez-Fernández, J., Garín-Aguilar, M.E., Hernández, C.G. and Bravo-Villa, G. (2014) Morphology and Mycelial Growth Rate of Pleurotus spp. Strains from the Mexican Mixtec Region. Brazilian Journal of Microbiology, 45, 861-872. http://dx.doi.org/10.1590/S1517-83822014000300016 